\title{
A Method for Assessing the Design Competency Profile (DCP)
}

\author{
Jean Brousseau, Ph.D., ing. \\ Engineering professor \\ Jean Brousseau@uqar.qc.ca
}

\author{
Abderrazak ElOuafi, Ph.D. \\ Engineering professor \\ Abderrazak ElOuafi@uqar.qc.ca
}

\author{
Suzie Loubert, ing. \\ Research assistant \\ Suzie Loubert@uqar.qc.ca
}

\author{
Université du Québec à Rimouski \\ Département de mathématiques, d'informatique et de génie
}

\begin{abstract}
Design is an integral part of the engineering profession and consequently, is a mandatory component of all engineering programs. Doubtless, new engineers need design skills in order to integrate the innovation task force of a company. Nevertheless, teamwork, which is an important component of the design competency, is also an obstacle to its development. Indeed, when working as a team, students have the tendency to specialize in certain tasks instead of taking profit from the experience to diversify their skills.

The paper introduces an approach to assess the Design Competency Profile (DCP) of a team and its members. The main components of the approach are the design competency frame of reference (design skills chart), the rubrics used to assess the deliverables, the tables of individual contributions, the team profile and the individual's profile. The individual DCP provides an overview of the competency of each team member and contributes to circumvent the side effects of teamwork. It can also help the students to understand the scope of the design competency and to develop the ability to identify and to address their own educational needs. Finally, in a program perspective, the DCP can help to manage the competency development in a global way.
\end{abstract}

\section{Introduction}

Design is the essence of the engineering profession and a fundamental component of any engineering program. Everything an engineer does is related to products sold by an enterprise to a customer (commercial or industrial products, services, systems, processes). It doesn't matter whether his duties are related to design, production, maintenance or managing, the engineer is part of the very broad product design and development team. Nowadays, no technical product could exist without the contribution of the engineers. Of course, as part of their learning, all engineering students must have the opportunity to understand the product development cycle deeply and to develop the skills needed to take part in the innovation task force of its company. The context is well recognised and clearly embedded in the Accreditation Criteria Procedures of the CEAB [1]. As far as design is concerned, the CEAB requires a significant experience and a minimum of 225 accreditation units out of a total of 1,950 (minimum).

It is well recognised that you cannot become a good engineer by reading books on design. Design is a multifaceted and cross-disciplinary competency [2]. Since it is acquired with experience [3], based on methodologies, techniques and tools [4], it is advisable to provide students with the opportunity to gain a variety of experiences throughout the full extent of their curriculum. During their curriculum, engineering students need to face significant design experiences based on the knowledge and skills acquired in other courses and involving team work. In the majority of engineering programs, there is a sequence of projectbased design courses beginning, most of the time, in the first semester. Such courses give real-world context for the development of design skills. In fact, the students may have the opportunity to work with live customers, meet necessary needs, solve authentic problems using modern tools, apply all the steps of the design process, deliver a functional prototype, manage a real project, understand the professional and ethical responsibilities of the engineer, work as a team with other students and produce oral and written documents.

In the project-based design courses, students have to deliver many artefacts such as project statement, concept report, detail and assembly drawings, electrical and electronics drawings, design final report, prototypes, and different manuals for assembly, maintenance, installation. Assessing design outcomes is challenging and time consuming task, mainly because outcomes are: numerous, diverse, carried out by team of students and the concrete expression of 
cross disciplinary skills. Rubrics are certainly the most popular and main tool for competency assessment. They are chart-like representations that detail the essential elements of specific learning tasks and describe the levels of achievement expected. Of course, everything should be done to increase the return on the investment in terms of knock-on effect on design education. With this aim in view, the students should be aware of the criteria and standards they have to reach before they start producing any artefact.

Very often in project-based courses, the students are asked to work in a team. Like in real work situations, students exploit the team members' strengths and resources instead of trying to diverse their skills. In a design education context, teamwork may be an obstacle to the development of design competency. In fact, teamwork may contribute to maintain the skill gaps in some students and have the effect of encouraging the specialisation. Because of the pressure to produce good design, the students do not seek to diversify their skills. Consequently, the design educator should try to circumvent the side effect of teamwork and give the team and its members a real feedback of their achievements.

The objective of this paper is to introduce the concept of Design Competency Profile (DCP) and present an approach to assess the team profile and the team-mate profile. Before it defines the idea of competency profile, the paper reminds the concept of competency, presents a frame of reference of the design competency (design skills chart) which is the foundation of the approach. Afterwards, the paper presents the main components of the approach: the rubrics used to assess the deliverables, the tables of individual contributions, the team profile and the individual's profile. Finally, it describes the context of its introduction in the engineering programs at UQAR and the next steps planned through a more complete integration of the profile in the engineering program.

\section{Design Competency - Frame of Reference}

Inspired by the definition adopted by the Association of Professional Orders of Québec (http://www.professions-quebec.org), the concept of competency refers to the knowledge, know-how and inter-personal skills required to carry out professional activities. When referring to the exercise of a profession, the concept of competence becomes more complex and takes particular dimensions. Indeed, professionals must demonstrate their competence in varied and multifaceted situations in the service of a client or employer, and in such a manner as to prevent such persons from sustaining prejudice. In addition, ethical and moral dimensions must therefore, be considered in assessing requirements and services.

In addition to the design content requirement, the CEAB looks on design as one of the essential attributes that all graduates must possess. The new Accreditation Criteria Procedures now recognise that a new graduate, at the time of graduation, must possess twelve attributes, going from the ability to solve problems, to the abilities to communicate, work in a team, design and so on. One could argue that the twelve attributes are all linked together and related to engineering design activities. Of course, design competency can be defined in a very broad sense or in a more restrictive way. What does design competency include? For example, are team work and communication skills included in the design competency or are they separate from it? Because a design engineer needs teamwork skills, it is coherent to include it in the definition of the design competency. According to the report titled "Towards a Blueprint for Educating Design Engineers: Design Competency" and written by NSERC Chairs in Design Engineering [3], the design competency roughly integrates the twelve attributes identified by the CEAB. Since a competency is a bundle of skills, knowledge, attitudes and behaviours required for effective performance of a real-world task or activity, it is logical to include all the components in the design competency.

On the other hand, project-based design courses are the perfect context for cross-disciplinary and design competency development. As suggested in [3], we adopted a general and broad definition of the design competency. Table 1 illustrates a simplified overview of our design competency frame of reference. The complete version of the design skill chart includes a general description of the professional context of the design competency, the goals in terms of outcomes and the standards (description of the expected levels). The frame of reference addresses what the students are expected to accomplish and the level of performance they are expected to reach. On table 1, the different elements of competence are identified with capital letters and numbers for further reference.

\section{Design Competency Profile}

Design competency profile gives an overview of how teams and students have demonstrated their design competency. It synthesises the assessment data gathered from rubric and other tools. Rubrics and others assessment tools give a detail view of the 
proficiency attained by the teams for a large number of elements. The profile goes further than that and summarizes the major conclusion of the assessment process.

Table 1. Design Competency

\begin{tabular}{|c|}
\hline Design Competency Elements \\
\hline $\begin{array}{l}\text { Professional Knowledge } \\
\text { Identify (P1) and take into account (P2) } \\
\text { - } \quad \text { Quality of life, safety, Ethics, Liability, Codes, Laws, } \\
\quad \text { Regulations, Standards, Intellectual property. } \\
\end{array}$ \\
\hline $\begin{array}{l}\text { Design Skills } \\
\text { Plan (D1) and apply (D2) the design process } \\
\text { - Problem definition, Needs identification, Specifications, } \\
\text { Concept generation, Proof of concept, Concept selection, } \\
\text { Product architecture, Detail design, Prototyping, design } \\
\text { refinement. } \\
\text { Use of appropriate design tools } \\
\text { - Common tools (D3): Information seeking, brain storming, } \\
\text { CAD modelling, detail drawings, electrical and electronics } \\
\text { drawings, functional analysis, } \\
\text { - Specialised tools (D4): TRIZ, Finite element method, etc. } \\
\text { Assess performance against criteria and constraints } \\
\text { - Apply knowledge for solving a design challenge (D5) } \\
\text { - Apply design rules from codes, standards, etc. for } \\
\text { dimensioning components (D6). } \\
\text { - Apply design methodologies like DFMA, lean design, } \\
\text { product cycle management to optimise a product (D7). } \\
\text { Make a decision (D8) } \\
\text { - Apply an appropriate method for making decisions at the } \\
\text { different design phases. }\end{array}$ \\
\hline $\begin{array}{l}\text { Operational Skills } \\
\text { - } \quad \text { Reach the goal of the project and overcome the project } \\
\text { difficulties }(\mathrm{O} 1) \text {. } \\
\text { - } \quad \text { Manage the unexpected situations }(\mathrm{O} 2) \text {. } \\
\end{array}$ \\
\hline $\begin{array}{l}\text { Experiential Skills (E1) } \\
\text { - Conduct investigations in order to reach valid conclusions. } \\
\text { - Test and refine a prototype }\end{array}$ \\
\hline $\begin{array}{l}\text { Social and Personal Skills } \\
\text { - Teamwork (SP1), Leadership (SP2), Professionalism (SP3), } \\
\text { Written communication (SP4), Design file organisation } \\
\text { (SP5), Oral communication (SP6), Negotiation (SP7) } \\
\end{array}$ \\
\hline $\begin{array}{l}\text { Cognitive Skills } \\
\text { - } \quad \text { Project Management (C1), Problem Solving and Creative } \\
\text { Strategies (C2), Management of Risk and Success Factors } \\
\text { (C3). }\end{array}$ \\
\hline
\end{tabular}

\subsection{Course and Deliverables}

Before presenting the details of the DCP, we will give some indication about the course in which the DCP has been introduced. This brief description will prove helpful to figure out the context of its introduction.

Project-based design courses are an important part (approximately one-sixth) of UQAR's engineering programs. During their first year, students undertake a design course that includes a project with a non-profit organization [2], in their third and fourth year design courses, students are encouraged to work with partners from the industry.

The approach for measuring the design profile has been integrated in the third year project-based course ( 6 credits, 2 semesters). As part of the course, the student teams work with an industry partner on projects that have a low to medium level of incertitude. Throughout the various stages, the students have to deliver a project statement, a concept report, detail and assembly drawings, electrical and electronic drawings, a final design report, different technical manuals (assembly, maintenance and installation), a complete and functional prototype, a poster, an oral presentation and a log book that includes all the technical analysis done when designing the product. Such a number of deliverables necessitates a lot of time for assessing the outcomes. However, the assessment process does not always have the desired impact, possibly because the feedback is not individual, too detailed and not global enough.

\subsection{Assessment Tools and DCP of a Team}

Rubrics are the basic tool that we use for assessing the design competency through the deliverables. Rubrics are chart-like representations that detail the essential elements of specific learning tasks and describe characteristics of the learning process at progressive levels of achievement [5-6]. They are a description of learning at different levels of development.

For each deliverable, we built a rubric. Since we want to track the competency development, the rubrics are constructed around the competency elements (objectives) instead of the content of the deliverables. The difference is important if the results of the assessment have to be used to draw the DCP. In order to translate the description of learning of a rubric into a mark associated with a deliverable, the competency elements involved in the production of each deliverable were weighted in such a manner that the result can be expressed in percentages. The rubric used a four level scale for scoring the outcomes: beyond expectations, come up to expectations, below expectations, and far from expectations.

Most of the competency elements of Table 1 are directly integrated in the rubric, but some of them could not be assessed with the rubrics used for scoring the deliverables. Those elements are the operational skills (O1-2), some of the social and personal skills (SP1-2-3-7) and the cognitive skills (C2-3). To assess the skills not included in the rubric, we use other tools. The first one is the meeting sheet used every week by the instructors during his meeting with the project teams. The sheet has specific sections for each 
competency element that needs to be continuously assessed. For the skills SP1-2-3, we also use selfassessment, team assessment and peer review assessment. The grids have been elaborated to assess teamwork, leadership and professionalism. The grids are based on our experience and not on research work. Additional work will have to be done on the subject.

All the tools (rubrics, meeting sheet and grids) have been integrated into a spreadsheet file. Through association, it is easy to synthesise the team performance related to the different skills and obtain the DCP of the team. The DCP is nothing else than the Design Competency Chart with an additional column that gives an indication of the team performance. In the DCP, the performance is described using four classification marks: I for insufficient, ND for not demonstrated, D for demonstrated and CD for clearly demonstrated. The transition from the rubrics to the DCP is done through relations that need to be established for each skill. For example, for the written communication skill, a global mark can be calculated from the different rubrics and the overall performance of the team can be established with the help of a rule. In the case a of communication skill, the following rule has been used: if score $\geq 85 \%$ then $C D$, if the score $\geq 60 \%$ and score $<85$ then D, if the score $<60 \%$ then I, else ND.

Figure 1 illustrates the main idea of the DCP. It simply shows that the DCP is the result of the integration and processing of all the data resulting from the assessment. Nevertheless, for each element of the design competency, rules have to be elaborated.

Figure 1. DCP of a Team

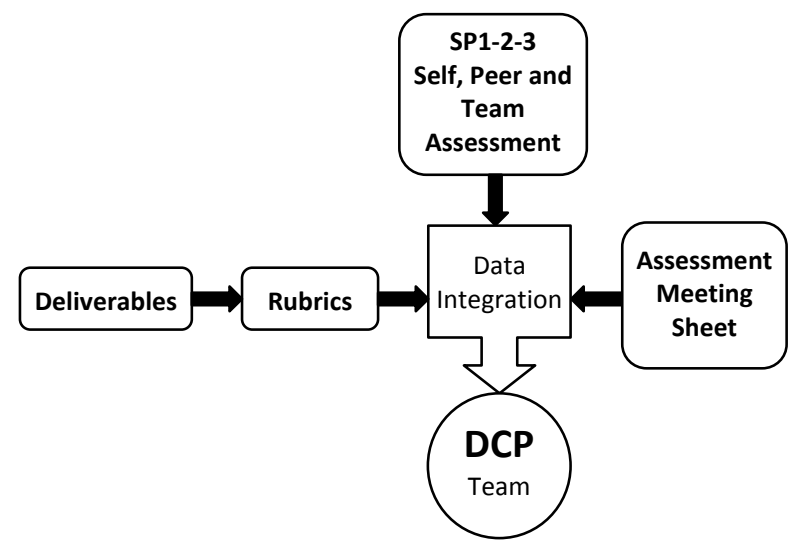

\subsection{DCP of Team Members}

The difficulty with the DCP of team members is to distinguish the contribution of each member. To this end, we introduce the table of individual contributions.
At the end of each project stage, the team must fill a table that identifies the contributions of each member. For each entry, the team must distribute 100 points between members. As an evidence of the agreement between team-mates, the table must be signed.

To be useful, easy to fill by the students and suitable for consensus, the table must not contain too many elements, 10 seem to be a good maximum. Each entry of the table must be formulated to be easily associated with one competency element of the frame of reference. At the end of the project, all the assessment information can be integrated, processed and used to draw the DCP of each member (see Figure 2). The table of contributions is essential to draw the DCP of individuals; it is also an efficient tool for revealing team conflicts or difficulties.

Figure 2. DCP of a Member

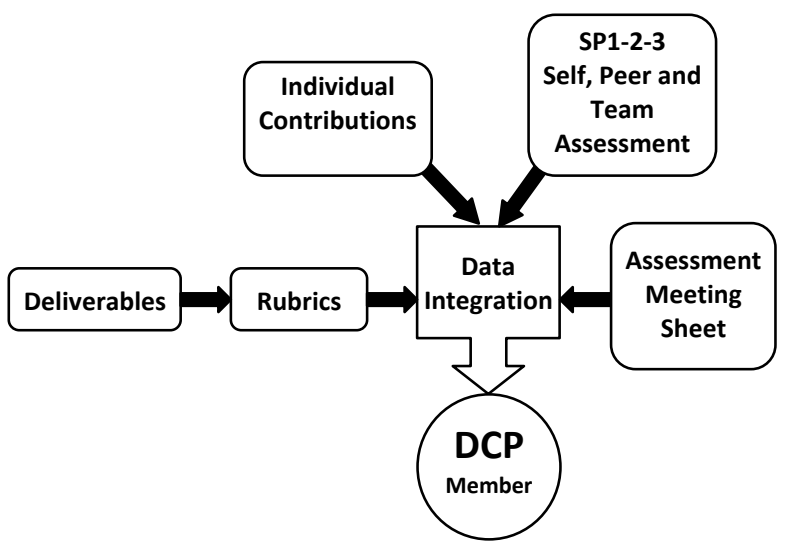

When integrating and processing the data, different parameters and many relations need to be established. As a first parameter, the level of a significant contribution has to be determined. In our case, we decided to set $(3 / 4 \times 100 \% / \mathrm{n})$ as a contribution important enough to be considered, where $n$ is the number of team members. For skills where the result can be expressed in percentages, the levels for the attribution of the classification marks CD (clearly demonstrated), D (demonstrated) and I (insufficient) has to be established. Depending of its contributions, the DCP of a student and that of a team can be different. For example, a student could have spent time working on one well written report, without having contributed to the other reports. In such a situation, the team could get a lower mark than the student. However, for some skills such as C2 and C3, and because we do not have a tool for assessing them for each team member, we just transfer the team mark to each member and add the subscript "T". For example, if the team gets a «D» for its way of managing the risks and success factors, each member gets a " $\mathrm{D}^{\mathrm{T}}$ " to indicate the transfer of the team mark. 
As an example of integration and processing of the assessment data, let us have a look at the information seeking skill. In all the reports (project statement, concept report and final report), the students must present the outcomes of their information searches. The rubrics used to assess the reports detail the levels of achievement expected in relation with the information seeking skill. For each report, a score can be extracted from the rubric. Three results are available for this specific skill, one for each report. In addition, the tables of contributions clearly indicate who was involved with this task and at each stage. From there, it is easy to assign a classification mark to each student. In a team, each member can have a different classification. One could have a "CD", another a "D", a third one an "I" and the last, who has not contributed, could get a "ND".

The figure below presents the DCP template that we use to communicate to the students their design competency profile.

Figure 4. DCP template

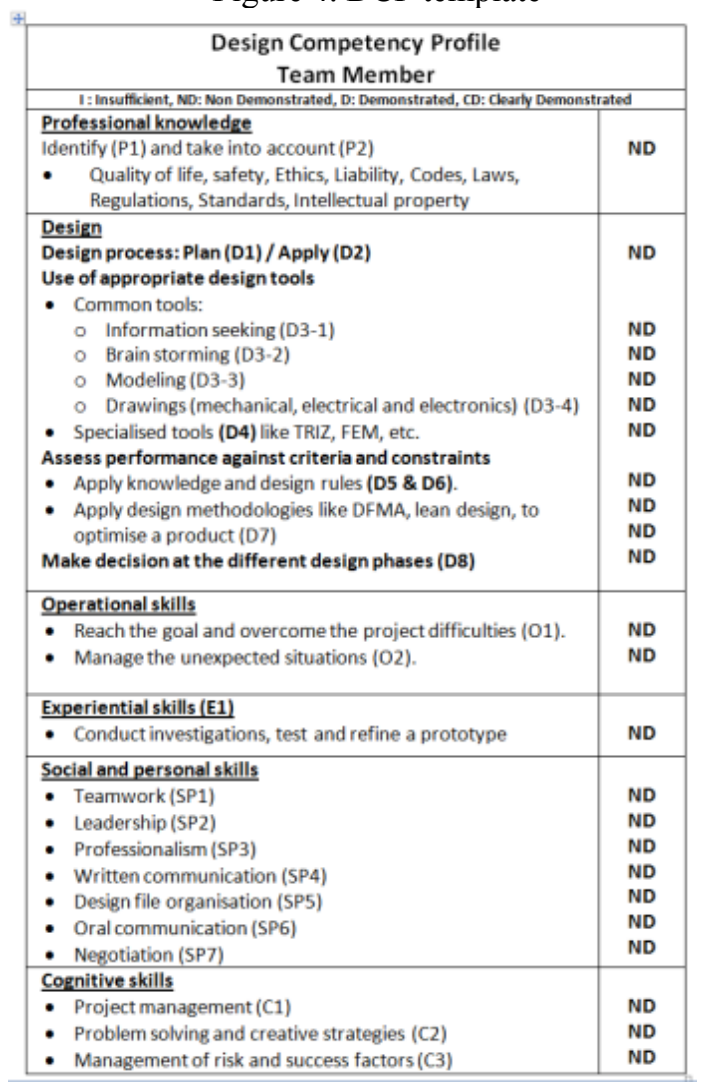

\section{Future Developments}

The DCP has been introduced in the "Mecatronic Design Project", which is part of the common core syllabus of the three engineering programs offered by
UQAR (Electromechanical, Mechanical and Electrical Engineering). The "Mecatronic Design Project" course is offered in the third year, is worth 6 credits and lasts two semesters. We chose this course because it was in the middle of the sequence of design related courses (see Figure 5). "Mecatronic Design Project" was the course that could give the maximum impact on design education.

Because it is not a senior project, the students and the professors of the next design courses (Design Projects I and II) can surely take advantage of the DCP. With the DCP in hand, the students get an overview of their competency, that can help understanding the scope of the design competency and develop the ability to identify and address their own educational needs. The professors, well informed of the competency profile of their students, can certainly use the information to incite the students to cover all the elements of the design competency during their senior project. The DCP is a tool that can help to manage the development of the competency globally instead of course by course. It is a tool for monitoring and tracking our student's competency development.

Figure 5. UQAR's sequence of design related courses

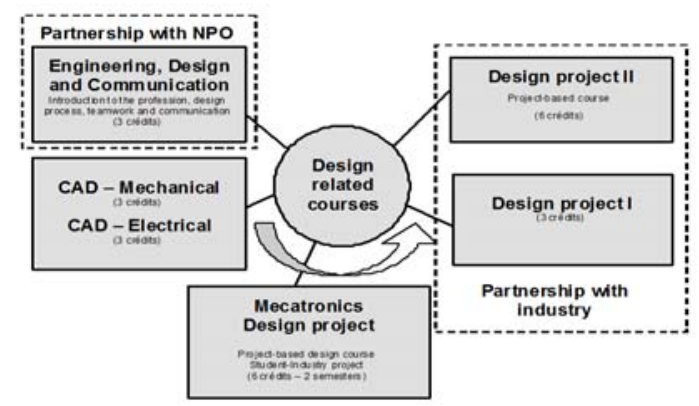

The next development that we plan to implement will be to extend the use of the DCP to all other design courses. To that end, we will have to harmonise the rubrics used in the different courses. The progressive levels of achievement have to be balanced between the different courses. The "beyond expectation" level in a freshman's project course may be the "come up to expectations" in the third year course and the "below expectations" in the fourth year course. The rubric used in the freshman's course should be built with all the elements and details needed to help students perform as expected. A detailed rubric is like a clear blueprint, not only for assessment purposes, but for learning purposes as well. However, the rubrics used in the fourth year course should specify the quality of work that characterizes each level of learning in more general ways and should be written with fewer details. 
Exactly like in real work situations, the feedback young engineers have from their superiors is overall, not detailed and presumes that the young engineers possess a certain level of competency. In such a context, the young engineers need to interpret the messages and make changes to solve a problem or adapt themselves to a situation. In order to implement the DCP throughout the curriculum, we need a complete and coherent package of rubrics for all sequences of design related courses. In addition, the DCP format should be adapted for the different courses.

\section{Conclusion}

Design is an integral part of the engineering profession and consequently, is a mandatory component of all engineering programs. Training a design engineer is a difficult task because the competency that he needs is a multifaceted and crossdisciplinary competency best acquired through experience. However, during their engineering studies, the students should develop all the elements of the design competency to some extent. Project-based design courses give a real-world context for the development of design skills. In such projects, students tackle real-world problems, are placed in the same context as professional engineers and gain valuable design experience while remaining in touch with professional design engineers. Nevertheless, teamwork, which is an important component of design courses, often leads to the exploitation of team members' strengths, which may have the effect of maintaining the skill gaps in some students. It takes a lot of effort to assess the outcomes of such courses, and it is quite natural to try and maximise its impact. Through rubrics, student teams receive instructor's comments for their results. Within the framework of one or two semester projects, they receive a lot of comments for their productions. Because of that, the overall picture is not easy to get.
The DCP proposes an approach that helps to summarize the skills that have been acquired. The DCP points out if a team has demonstrated the different elements of the design competency. Without the information on the individual contributions of the team-mates, it is impossible to give a clear feedback to each student. For that reason, we introduced the table of individual contributions. At the end of each project stage, the teams have to fill the table which indicates the tasks completed by each member. With this new information, it is possible to integrate and process the assessment data and deduce the DCP of each student. The DCP is then a practical tool that helps the students to address their weakness and educational needs. If the DCP is introduced in a sequence of project-based courses, the DCP can contribute to the global management of the development of the competency. Well informed of the competency profile of its students, an instructor can incite the students to diversify more.

\section{References}

[1] CEAB: Canadian Engineering Accreditation Board, Accreditation criteria and procedures, 2009.

[2] The NSERC Chairs in Design Engineering and Chairs in Environmental Design Engineering, "Towards a Blueprint for Educating Design Engineers: Design Competency", February 21, 2005.

[3] Billy V. Koen, "Toward a Strategy for Teaching Engineering Design”, Journal of Engineering Education, July 1994.

[4] J.W. Dally and G.M. Zhang, "A Freshman Engineering Design Course", Journal of Engineering Education, April 1993.

[4] Jean Brousseau, Abderrazak ElOuafi and Suzie Loubert, "Service Learning: A Powerful Approach to the Introduction of Engineering Design for Freshmen, CDEN/C2E2 Conference 2007, July 22-24, University of Manitoba, Winnipeg, Canada.

[5] Gérard Scallon, L'évaluation des apprentissages dans une approche par competences, ERPI, 2004.

[6] Sue Fostaty Young and Robert J. Wilson, Assessment \& Learning - The ICE Approach, Portage \& Main Press, 2000. 